\title{
A case of complete double layer stents fracture in the right coronary artery
}

\author{
Xuhe Gong^, Daokuo Yao \\ Department of Cardiology, Beijing Friendship Hospital, Capital Medical University, Beijing, China \\ Correspondence to: Daokuo Yao. Department of Cardiology, Beijing Friendship Hospital, Capital Medical University, 95 Yongan Road, Xicheng \\ District, Beijing 100050, China. Email: yaodaokuo@126.com.
}

Submitted Dec 19, 2020. Accepted for publication Mar 30, 2021.

doi: 10.21037/qims-20-1374

View this article at: http://dx.doi.org/10.21037/qims-20-1374

\section{Introduction}

Stent fracture is a rare and dangerous complication following coronary stenting. It can cause stent restenosis or thrombus, and the incidence rate of stent fracture is $1.7-7 \%$ (1). Treatment of stent rupture depends on the type of stent rupture and the severity of clinical events. Comprehensive analysis of the possible causes of stent fracture, careful observation of morphology, and consideration of patients' symptoms will help select a reasonable treatment strategy.

\section{Case presentation}

A 67-year-old man was hospitalized in April 2020 due to chest pain. The patient had a 5-year history of precordial chest pain, and the chest pain worsened for 1 month. He had been diagnosed with acute inferior myocardial infarction 5 years ago, at which time angiography had revealed double vessel disease involving the diagonal branch and proximal right coronary artery (RCA) (Figure 1A). The patient had undergone percutaneous coronary intervention (PCI) with a $3.5 \mathrm{~mm} \times 29 \mathrm{~mm}$ Partner $^{\mathrm{TM}}$ stent (sirolimuseluting stent, Lepu Medical Technology Co., Ltd., Beijing, China) in RCA (Figure 1B). His symptoms had been relieved after the PCI, and secondary preventative medications were taken regularly (clopidogrel was stopped after 1 year, aspirin and statin were continued).

Unfortunately, 2 years ago, the patient had another acute inferior wall myocardial infarction. Urgent coronary angiography showed visible stents in the RCA's proximal and middle segments, with in-stent total occlusion (Figure 1C). After the thrombus was aspirated, a $4.0 \mathrm{~mm} \times 33 \mathrm{~mm}$ Partner stent was implanted in the RCA (Figure 1D), considering that the prior smaller stent may have been associated with re-occlusion. His past medical history included hypertension for 10 years, hyperlipidemia for 5 years, and smoking for 40 years. His brother had coronary heart disease and had undergone stent implantation.

After hospitalization, no obvious abnormalities were detected upon physical examination, and secondary prevention treatment was prescribed. Tests revealed that the patient was negative for creatine kinase- $\mathrm{MB}$, troponin, and $\mathrm{N}$-terminal pro-brain natriuretic peptide. Echocardiography revealed left ventricular ejection fraction $(68 \%)$ was in the normal range, and the motion of the basal segment of the posterior wall and the inferior wall of the left ventricle was slightly weakened. Coronary angiography revealed a zigzag shape and visible stents in the RCA's proximal segments; stent fracture could be seen at the RCA first turning point (Figure 1E,F), with coronary blood flow of grade TIMI 3.

An optical coherence tomography (OCT) catheter (ImageWire, LightLab Imaging, Westford, MA, USA) was used for further evaluation. We found a complete 2-layer stent fracture in the proximal part of the RCA with a length of $1.3 \mathrm{~mm}$ without stent struts in the middle of the prior stents; the mean diameter of the lumen without struts was $4.59 \mathrm{~mm}$ (Figure 1G). Considering this patient's careful consideration with atypical chest pain, no basis of

\footnotetext{
^ ORCID: 0000-0002-0513-6674.
} 

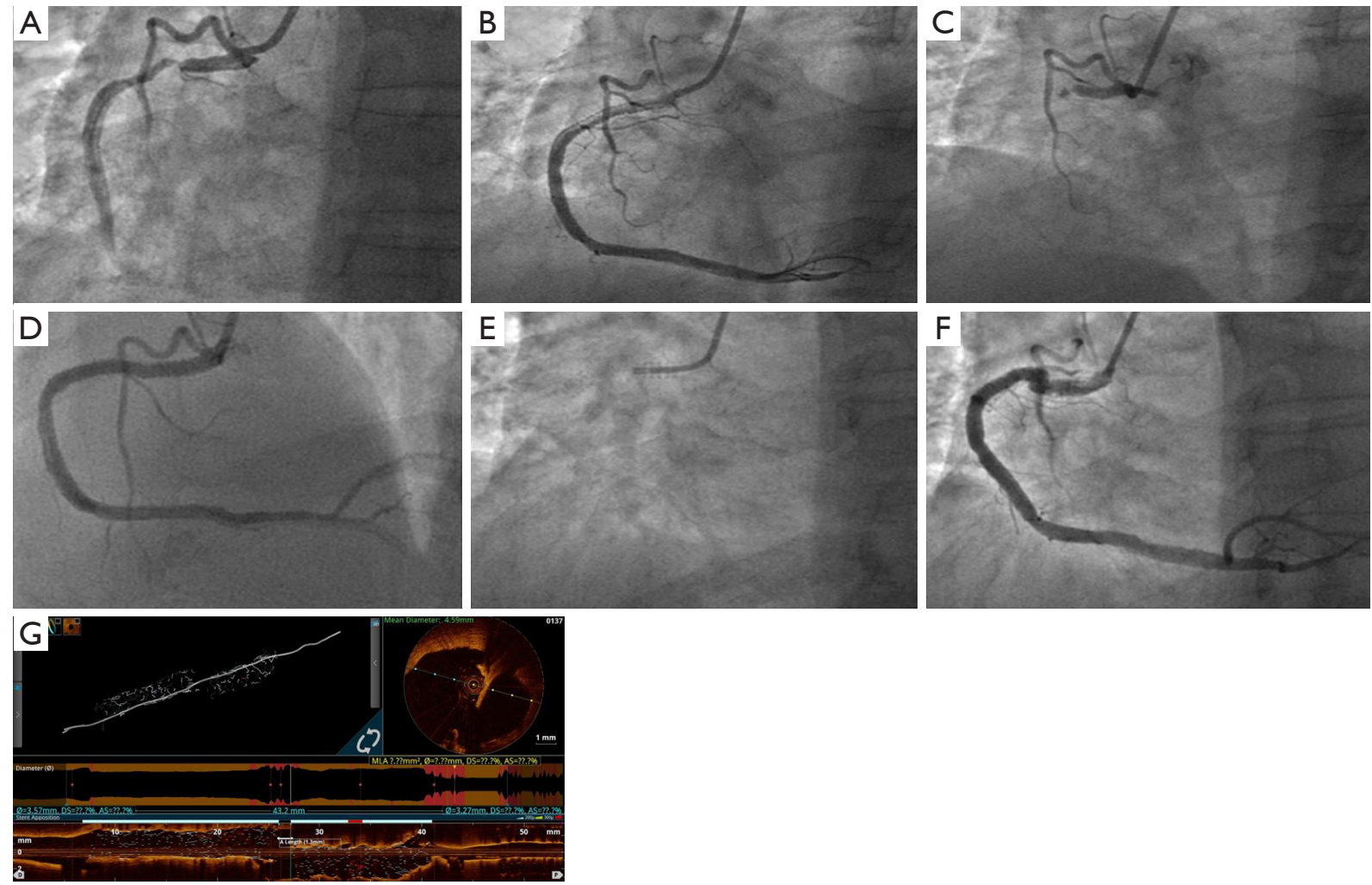

Figure 1 Images of coronary angiography and stent fracture in the RCA by OCT. (A,B) Images of coronary angiography and PCI 5 years ago. Severe stenosis in the proximal segment of RCA (A); post-stent angiography of RCA (B). (C,D) Images of coronary angiography and PCI 2 years ago, acute occlusion in the proximal segment of RCA (C), post-stent angiography of RCA (D). (E,F) Images of coronary angiography with complete stent fracture. Stents fracture in proximal RCA (E), zig-zag shape, and stent fracture at the first turning point of RCA with blood flow of grade TIMI 3 (F). (G) Images of stent fracture in the RCA by OCT. RCA, right coronary artery; OCT, optical coherence tomography; PCI, percutaneous coronary intervention.

myocardial ischemia, and RCA blood flow unobstructed, we did not perform any further interventional measures. The patient was discharged 2 days later, and no recurrent chest discomfort was reported during the 3 -month follow-up.

\section{Discussion}

This report describes a case of a rare complete doublelayer stent fracture in a 67-year-old man. The patient had displayed acute inferior wall myocardial infarction 5 and 3 years before this admission and was treated with stent implantation on both of those occasions. Coronary angiography revealed a zig-zag shape with a possible stent fracture in the RCA. The fracture morphology of the stent was observed by OCT imaging. Stent fracture is a rare complication after PCI, leading to restenosis, thrombosis, vessel injury, and aneurysm formation $(2,3)$.

Reports have shown that the coronary artery's motion is the main cause of fracture, whereby angulation of the coronary artery and shear stress potency near the proximal portion of the coronary become changed after stenting (4). The stent fracture was associated with a long-stented segment, RCA location, and metal overlap (5). Moreover, Ge et al. found that stent fracture is associated with higher mortality in patients with type- 2 diabetes treated by implanting a second-generation drug-eluting stent, and type IV stent fracture was seen more often in patients with diabetes (6). For the case featured in this report, the proximal RCA location with the long stent, motion, and shear stress may have been the main reason for stent fracture. Another possible reason for stent fracture may have been related to the bigger size stent implantation within the 
smaller one. The struts of the first stent of diameter $3.5 \mathrm{~mm}$ may have been damaged with post-dilation of the $4.0 \mathrm{~mm}$ non-compliant balloon. The reason for the fracture of the second stent strut was not clear.

Several management options for stent fracture include conservation, use of the stent-in-stent technique, and surgical correction. The treatment principles depend on the type of stent fracture and the severity of clinical events. For stent fracture-induced restenosis or thrombosis, it is generally recommended to try to avoid re-stent implantation. Additionally, long-term antiplatelet therapy should be used regardless of whether or not clinical events accompany stent fracture. For our patient, conservative management depended on the appearance of enough coronary lumen area with good antegrade blood flow through the complete stent fracture. At the time of coronary angiography, the zig-zag part was more like 2 separated double-layer stents with the no-stent area between. As in-stent restenosis or thrombosis was not present in the OCT images, and there was no lesion stenosis in the area between the stents, conservative therapy was reasonable. It was suggested that during PCI, we should attach great importance to the anatomic characteristics of the coronary artery and avoid long stent implantation in severe tortuous, angled, or calcified vessels.

\section{Conclusions}

Stent fracture is a rare and dangerous complication that may follow coronary stenting. We should analyze the causes of stent rupture, carefully observe the form of stent rupture, and combine these findings with patients' clinical manifestations to optimize patient outcomes.

\section{Acknowledgments}

Funding: This study was supported by the National Natural Science Foundation of China (81600196) and Beijing Municipal Administration of Hospitals' Youth Programme (QML20200106).

\section{Footnote}

Conflicts of Interest: Both authors have completed the ICMJE uniform disclosure form (available at http://dx.doi. org/10.21037/qims-20-1374). XG reports the National Natural Science Foundation of China and Beijing Municipal
Administration of Hospitals' Youth Programme Funding for this study. The other authors have no conflicts of interest to declare.

Ethical Statement: The authors are accountable for all aspects of the work in ensuring that questions related to the accuracy or integrity of any part of the work are appropriately investigated and resolved. All procedures performed in studies involving human participants were following the ethical standards of the institutional and/ or national research committee(s) and with the Helsinki Declaration (as revised in 2013). The patient provided written informed consent.

Open Access Statement: This is an Open Access article distributed in accordance with the Creative Commons Attribution-NonCommercial-NoDerivs 4.0 International License (CC BY-NC-ND 4.0), which permits the noncommercial replication and distribution of the article with the strict proviso that no changes or edits are made and the original work is properly cited (including links to both the formal publication through the relevant DOI and the license). See: https://creativecommons.org/ licenses/by-nc-nd/4.0/.

\section{References}

1. Nakazawa G, Finn AV, Vorpahl M, Ladich E, Kutys R, Balazs I, Kolodgie FD, Virmani R. Incidence and predictors of drug-eluting stent fracture in human coronary artery a pathologic analysis. J Am Coll Cardiol 2009;54:1924-31.

2. Chhatriwalla AK, Cam A, Unzek S, Bhatt DL, Raymond RE, Lincoff AM, Whitlow PL, Ellis SG, Tuzcu EM, Kapadia SR. Drug-eluting stent fracture and acute coronary syndrome. Cardiovasc Revasc Med 2009;10:166-71.

3. Del Trigo M, Jimenez-Quevedo P, Fernandez-Golfin C, Vaño E, Delgado-Bolton R, Alfonso F, Gonzalo N, Kallmeyer A, Montes L, Escribano N, HernandezAntolin R, Macaya C. Very late mycotic pseudoaneurysm associated with drug-eluting stent fracture. Circulation 2012;125:390-2.

4. Kang WC, Moon C 2nd, Ahn TH, Shin EK. Multiple stent strut fracture-induced restenosis in a diffuse long lesion treated with overlapping heterogeneous drugeluting stent. Int J Cardiol 2008;130:e30-3. 
5. Yang TH, Kim DI, Park SG, Seo JS, Cho HJ, Seol SH, Kim SM, Kim DK, Kim DS. Clinical characteristics of stent fracture after sirolimus-eluting stent implantation. Int J Cardiol 2009;131:212-6.

6. Ge Z, Liu ZZ, Kan J, Zhang JJ, Li SJ, Tian NL, Ye F,

Cite this article as: Gong X, Yao D. A case of complete double layer stents fracture in the right coronary artery. Quant Imaging Med Surg 2021;11(11):4703-4706. doi: 10.21037/qims-20-1374
Qian XS, Yang S, Chen MX, Rab TS, Chen SL. Stent fracture is associated with a higher mortality in patients with type-2 diabetes treated by implantation of a secondgeneration drug-eluting stent. Int J Cardiovasc Imaging 2017;33:1873-81. 